\title{
The risk-based approach to ATMP development - Generally accepted by regulators but infrequently used by companies
}

\author{
M. Kooijman ${ }^{\text {a,* }}$, P.J.K. van Meer ${ }^{\text {b }}$, C.C. Gispen-de Wied ${ }^{c}$, E.H.M. Moors ${ }^{\text {a }}$, M.P. Hekkert ${ }^{\text {a }}$, H. Schellekens ${ }^{\text {a,b }}$ \\ ${ }^{a}$ Innovation Studies, Copernicus Institute of Sustainable Development, Utrecht University, PO Box 80115, 3508 TC Utrecht, The Netherlands \\ ${ }^{\mathrm{b}}$ Utrecht Institute of Pharmaceutical Sciences, Department of Pharmaceutics, Utrecht University, PO Box 80082, 3508 TB Utrecht, The Netherlands \\ ${ }^{\mathrm{c}}$ Medicines Evaluation Board, Graadt van Roggenweg 500, 3531 AH Utrecht, The Netherlands
}

\section{A R T I C L E I N F O}

\section{Article history:}

Received 24 July 2013

Available online 7 August 2013

\section{Keywords:}

Advanced therapy medicinal products

Risk-based approach

Scientific advice

Science-driven non-clinical drug

development

Regulatory science

\begin{abstract}
A B S T R A C T
Advanced therapy medicinal products (ATMPs) are the cutting edge of drug innovation. ATMPs have different challenges than other drug classes. To accommodate these challenges and facilitate science-driven development, flexibility in the requirements to demonstrate the safety and efficacy of this rapidly evolving drug class is necessary. To create flexibility, the European Union introduced the risk-based approach. This approach provides the possibility of omitting guideline-based studies based on risk analyses. To gain insight into the effect of the risk-based approach on the non-clinical development of ATMPs, two questions are addressed in this paper. Firstly, "Do companies use a risk-based approach for the non-clinical development of ATMPs?" and, secondly, "Does the Committee for Medicinal Products for Human Use (CHMP) of the European Medicines Agency (EMA) accept non-clinical development programs based on the risk-based approach?" Scientific advice letters formulated by the CHMP were analyzed. The risk-based approach was used to justify deviations from the guidelines in the majority (75\%) of the cases. The CHMP accepted $40 \%$ of the proposals to omit studies and stated that additional data was necessary to make an informed decision for $35 \%$ of the proposals. This indicates that the riskbased approach facilitates the science-driven development of ATMPs.
\end{abstract}

(c) 2013 Elsevier Inc. All rights reserved.

\section{Introduction}

Advanced therapy medicinal products (ATMPs), the cutting edge of drug innovation, hold promise to offer a cure for a variety of diseases for which there are no satisfactory therapies, such as cancer, inherited monogenic diseases, cardiovascular disease, Parkinson's disease, diabetes and arthritis (Jekerle et al., 2010; Jilma, 2010; Klug et al., 2012; Maciulaitis et al., 2012; Schneider et al., 2010; Vamvakas et al., 2011). ATMPs are diverse in nature, comprising gene therapy medicinal products (GTMPs) ${ }^{1}$ and cell-based medicinal products (CBMPs) (including cell therapy ${ }^{2}$ and tissue engi-

\footnotetext{
* Corresponding author. Address: Utrecht University, Heidelberglaan 2, 3584 CS Utrecht, The Netherlands. Fax: +31302512746.

E-mail address: m.kooijman@uu.nl (M. Kooijman).

1 Definition of GTMPs: "Gene therapy products consist of recombinant nucleic acids administered to humans with a view to regulating, repairing, replacing, adding or deleting a genetic sequence, and whereby its effect relates directly to the recombinant sequence or the product of genetic expression of this sequence. Novel recombinant or vector-based vaccines against infectious diseases are also specifically excluded from the definition of gene therapy products" (Jekerle et al., 2010, p. 6).

2 Definition of cell therapy: "Cell therapy medicinal products contain or consist of substantially manipulated cells and have properties for treating, preventing, or diagnosing a disease through the pharmacological, immunological and metabolic action of the cells or tissues" (Jekerle et al., 2010, p. 6).
}

neering $)^{3}$. These products have different characteristics than small molecule and biotechnology-derived drugs. These differences entail that ATMPs also have a different risk profile and other challenges for safety evaluations, such as the effects of ineffective integration into to the patient's body systems, cells and genes and immune responses. Moreover, some ATMPs can stimulate tumor growth (Mavilio, 2012; Schneider et al., 2010).

To accommodate the development of this new class of pharmaceuticals, the European Union created regulation EC 1394/2007 on ATMPs and revised Directive 2001/83 on the community code relating to medicinal products for human use (Klug et al., 2012). As a general principle, ATMPs have to fulfill the same scientific and regulatory standards as other medicinal products (European Union, 2001, 2007; Jekerle et al., 2010; Klug et al., 2012; Mavilio, 2012). Nevertheless, regulation EC 1394/2007 together with the technical requirements contained in revised Annex I of Directive 2001/83/EC introduce specific requirements for ATMPs (European Union, 2001; Klug et al., 2012). These specific requirements are high level requirements because the type and amount of data necessary to demonstrate the quality, safety and efficacy of diverse of

\footnotetext{
${ }^{3}$ Definition of tissue engineering products: "It should be noted that it is the intended action (i.e., treating, preventing or diagnosis a disease for cell therapy medicinal products vs. regenerating, repairing, replacing a human tissue for tissue engineered products) that will differentiate a cell therapy medicinal product from a tissue engineered product" (Jekerle et al., 2010, p. 6).
} 
ATMPs is highly specific (Jekerle et al., 2010). Sufficient flexibility in the development of ATMPs is important to anticipate the rapid evolution of science and technology in the field of ATMPs (Jekerle et al., 2010; Schneider et al., 2010). The technical requirements are therefore further explored in several class-specific guidelines of the EMA (Jekerle et al., 2010; Schneider et al., 2010).

To create more flexibility, the legislation and guidelines concerning ATMPs recommend companies to use a risk-based approach during development (European Medicines Agency, 2013; Klug et al., 2012; Jekerle et al., 2010; Cohen-Haguenauer, 2013). The EMA defined the risk-based approach as "a strategy aiming to determine the extent of quality, non-clinical and clinical data to be included in the Marketing Authorisation Application (MAA), in accordance with the scientific guidelines relating to the quality, safety and efficacy of medicinal products and to justify any deviation from technical requirement as defined in Annex I, part IV of Directive 2001/83/ EC" (European Medicines Agency, 2013, p. 4). The purpose of the risk-based approach is to obtain a profile of the risks associated with the use of a specific ATMP by identifying the various risks 4 associated with the clinical use and the risk factors ${ }^{5}$ inherent to the ATMP with respect to quality, safety and efficacy.

The risk-based approach is an ongoing process whereby the manufacturer conducts risk analyses at the beginning and during product development (European Medicines Agency, 2013; Jekerle et al., 2010). The amount of data required for MAA depends on the level of risk, state of knowledge about the product under development and experience of the manufacturer with other ATMPs (Cohen-Haguenauer, 2013). The final risk profile will take shape as a result of the consolidation of the identified risk factors ( $\mathrm{Co}-$ hen-Haguenauer, 2013).

The purpose of the risk-based approach in the development of ATMPs is to create a framework wherein it is encouraged to take into account continuously evolving science and technology in order to design a tailor-made ATMP development program. The approach aims to provide the possibility of moving away from guideline-based ATMP development and to facilitate science-driven development strategies of ATMPs. The risk profile of an ATMP can point out that some, requirements prescribed in the EMA guidelines or in the Directive 2001/83/EC are redundant and that other strategies are more relevant to establish the quality, safety and efficacy of the product under study (European Medicines Agency, 2013).

The aim of this paper was to study whether the risk-based approach facilitates science-driven non-clinical drug development. To gain insight into the effect of the risk-based approach at the level of non-clinical development of ATMPs, two questions are addressed in this paper. Firstly, "Do companies use a risk-based approach for the non-clinical development of ATMPs?" and, secondly, "Does the Committee for Medicinal Products for Human Use (CHMP) of the EMA accept non-clinical development programs based on the riskbased approach?"

Only three ATMPs have received market approval in the EU. This sample is too limited for an analysis of the drug registration dossiers of those ATMPs. We therefore analyzed the scientific advice letters formulated by the CHMP in order to gain insight into the use and acceptance of the risk-based approach for the non-clinical development of currently developed ATMPs. Companies can

\footnotetext{
4 The EMA defines risks as "potential unfavourable effect that can be attributed to the clinical use of ATMP and is of concern to the patient and/or to other populations (e.g. caregivers and offspring)" (European Medicines Agency, 2013, p. 4). Examples of risks are: unwanted immunogenicity, disease transmission, tumor formation and treatment failure.

5 The EMA defines risk factors as "qualitative or quantitative characteristic that contributes to a specific risk following the handling and/or administration of an ATMP" (European Medicines Agency, 2013, p. 4). Risk factors are associated with the nature of the product, biodistribution and manufacturing issues.
}

apply for scientific advice of the CHMP at every stage of product development. In their scientific advice request, companies can pose questions related to quality, non-clinical and clinical development. The Scientific Advice Working Party of the(SAWP) answers the questions in close consultation with relevant working parties such as the Committee for Advanced Therapies (CAT), the Biologics Working Party (BWP) and the Safety Working Party (SWP) and prepares a scientific advice letter including the background on the disease and the product provided by the company, the questions posed by the company and the answers formulated by the SAWP and adopted by the CHMP. The questions posed by the manufactures indicate if and how often manufacturers use a risk-based approach. The answer provides insight into if and how often the CHMP accepts non-clinical development programs using the riskbased approach.

\section{Methodology}

The scientific advice letters of the CHMP concerning ATMPs between 2009 and 2012 were accessed at the Dutch Medicines Evaluation Board. The letters wherein the applicant sought advice about non-clinical development were selected for this analysis. The questions in the section "Questions on Toxico-Pharmacological Development" were used to evaluate whether companies proposed non-clinical development programs using a risk-based approach. The answers to these questions were used to assess to what extent the CHMP accepts innovative risk-based non-clinical programs for ATMP.

The aim of the risk-based approach is to determine the extent of data necessary for a marketing application and to justify any deviation from the requirements. Questions that could be related to deviating from the standard requirements were included and attributed to the following categories: (1) questions that proposed to do no animal studies; (2) questions that proposed to do one or two animal studies; (3) questions that proposed to not do repeat-dose toxicity studies in animals (4) questions that proposed to not do carcinogenicity studies in animals and (5) questions that proposed to not do reproduction toxicity studies in animals. These categories were selected because using a risk-based approach to justify the omission of chronic animal studies is most interesting since these studies are the most time-consuming and expensive of the regulatory required studies. Questions which could not be related to these categories were excluded. To determine whether companies used the risk-based approach to justify omitting a study, the line of argumentation used by the manufacturer was analyzed. The line of argumentation to not conduct animal studies was classified as (1) based on a risk analysis when companies argued that based on current knowledge and/or available data, the study would be redundant, (2) not based on a risk analysis when companies used no argument or other arguments, for example that the study was not feasible.

To evaluate whether the CHMP endorses risk-based non-clinical programs for ATMP, the answers of the CHMP to the questions classified as risk-based were analyzed and referred to the following categories: (1) proposal not accepted, (2) more information is necessary to confirm the provided line of argumentation, (3) proposal accepted and (4) no answer. The ATMPs and manufacturers were anonymized.

\section{Results}

Between 2009 and 2012, pharmaceutical companies requested scientific advice 80 times for 66 different ATMPs of the CHMP. The scientific advice letters concerned 48 CBMP and 18 GTMP. Fifty letters (for 48 different products) included questions related to 
Table 1

Overview of advice.

\begin{tabular}{ll}
\hline Issues discussed in scientific advice letters & \\
\hline Non-clinical & 9 \\
Non-clinical and quality & 7 \\
Non-clinical and clinical & 5 \\
Non-clinical, quality and clinical & 29 \\
Quality & 5 \\
Quality and clinical & 4 \\
Clinical & 21 \\
Total & 80 \\
\hline
\end{tabular}

non-clinical development, 59 letters included questions related to clinical development and 45 included questions related to quality control (see Table 1).

Of the 50 scientific advice letters including questions related to non-clinical development, advice was requested for the non-clinical development of 14 GTMPs and 34 CBMPs (follow-up advice was requested for two CBMPs) (Table 2). This corresponds with earlier findings that three-quarters of the ATMPs under development are CBMPs (Maciulaitis et al., 2012). Sixteen products of these 50 were designated as an Orphan Medicinal Product. Eight advice letters concerned ATMPs developed by big pharmaceutical companies (in the top 100 based on total sales in 2011). The other 42 ATMPs were developed by other companies. This result supports the conclusion of Maciulaitis et al. that "the vast majority of stakeholders developing ATMPs are academic institutions, charities, SMEs, or other small companies" (Maciulaitis et al., 2012, p. 479).

In the fifty scientific advice letters related to the non-clinical development of ATMPs, companies proposed to deviate from the standard requirements in 29 scientific advice letters (60\%). In these 29 letters 48 proposals to omit animal studies were done (Table 3 ). Six times companies proposed to do no (2) or only a few animal tests (4). In the other letters companies proposed to omit specific animal studies: repeat-dose toxicity testing (10), aspects of carcinogenicity testing (15) or aspects of reproductive toxicity testing (17).

\subsection{No animal studies}

Companies proposed to not conduct animal tests for two ATMPs. The companies argued that, due to a lack of adequate animal models, it was not relevant to do animal studies. In both cases, the CHMP agreed with the company's opinion that animal tests were not relevant. In one of these cases, the availability of "clinical use for over 10 years (more than 200 patients treated) without any serious events being reported" was decisive "to support the safety of the product and that no additional animal experiments are called for".

\subsection{Few animal studies}

Performing only a few animal studies for the non-clinical development of ATMP was proposed for four products. In two cases, the companies argued that additional relevant animal studies were not possible due to the nature of the product. In one of these cases, the CHMP was not convinced by the argumentation that no other relevant studies were possible and stated that the company "should justify their approach not to perform further studies using an animal equivalent". In the other case, the CHMP agreed with the proposed approach but argued that if (non)clinical data raised concerns, a homologous animal model might become necessary.

In the other two scientific advice letters, the companies reasoned that the available clinical data in combination with the non-clinical pharmacology study made additional animal studies redundant. The CHMP agreed that no dedicated toxicology studies were necessary, but the CHMP encouraged one company to add toxicological endpoints to the planned non-clinical pharmacology study.

\subsection{No repeat-dose toxicity studies in animals}

Ten pharmaceutical companies proposed to do no repeat-dose toxicity studies in animals. For eight ATMPs, multiple administrations in human patients were not anticipated, and the pharmaceutical companies therefore argued that there would be no need for repeat-dose toxicity studies. In six cases, the CHMP did not respond, while in two cases, the CHMP explicitly agreed that conducting a repeat-dose study would not be relevant. In one case, the company did not provide a rationale to omit repeat-dose toxicity testing. The CHMP emphasized in its answer to this company that a repeat-dose study would be necessary if readministration was anticipated in patients. In one case, the company argued that it would not be possible to assess repeat-dose toxicity because no relevant animal model was available. The CHMP did not agree with the company and advised the company to conduct repeat-dose toxicity studies in minipigs with a homologous product.

\subsection{No carcinogenicity studies in animals}

In fifteen scientific advice requests, the applicant proposed omitting carcinogenicity studies in animals. Thirteen times, companies argued that based on the available data from in vitro or animal studies, it was concluded that the risk of carcinogenicity was negligible. In two requests, the companies also added that there was no animal model available to conduct carcinogenicity studies. In three cases, the CHMP advised companies to conduct additional (in vitro or in vivo) carcinogenicity tests to exclude potential risks. The CHMP concluded that more information was necessary to make an informed judgment in five cases. The CHMP agreed with the proposal in six cases. In four cases, the CHMP had the view that sufficient knowledge was available about the carcinogenic potential of the ATMP. In one case, the CHMP agreed with omitting the test because the product was developed for a life-threatening and debilitating disease, but added that carcinogenicity "may gain higher importance if the therapy is successful".In the sixth case, the CHMP agreed with the omission of an animal study because "at present no applicable in vivo test system exists". One company proposed omitting carcinogenicity testing but provided no argument. The CHMP advised the company to gather more information to increase the understanding about the potential carcinogenicity risk of the ATMP. Another company argued that carcinogenicity testing was not feasible. The CHMP did not agree with this company and advised the company to gain more knowledge about the carcinogenic potential of the ATMP because that knowledge is warranted to assess the benefit/risk ratio.

\subsection{No reproductive toxicity studies animals}

In seventeen scientific advice requests, companies proposed omitting reproductive toxicity studies in animals. In two cases, the scientific advice letter did not describe any argumentation to justify omitting reproductive toxicity studies in animals provided by the manufacturer. Nevertheless, the CHMP responded to one proposal by stating that more supporting evidence was necessary to judge whether the proposal would be acceptable for marketing authorization.

Only one manufacturer also used the lack of an animal model as an argument to omit reproductive toxicity studies in animals. The CHMP did not agree with this proposal because they held the opinion that the clinical data were too limited and that a relevant animal model was available. In the remaining advice letters, the manufacturers used the risk-based approach to support their 
Table 2

Overview of scientific advice letters wherein non-clinical development was discussed.

\begin{tabular}{|c|c|c|c|c|c|}
\hline & \multicolumn{3}{|l|}{ Product class } & \multicolumn{2}{|c|}{$\underline{\text { Orphan drug status }}$} \\
\hline & CBMP (follow-up (FU) advice) & GTMP & Total (FU advice) & Yes (FU advice) & No (FU advice) \\
\hline 2009 & 8 & 2 & 10 & 4 & 6 \\
\hline 2010 & $6(1)$ & 6 & $12(1)$ & 4 & $8(1)$ \\
\hline 2011 & 9 & 4 & 13 & 5 & 8 \\
\hline 2012 & $11(1)$ & 2 & $13(1)$ & $4(1)$ & 10 \\
\hline Total & $34(2)$ & 14 & $48(2)$ & $16(1)$ & $32(1)$ \\
\hline
\end{tabular}

Table 3

Overview of companies requesting to deviate from standard requirements.

\begin{tabular}{|c|c|c|c|c|c|c|}
\hline ATMP & $\begin{array}{l}\text { No } \\
\text { animal } \\
\text { studies }\end{array}$ & $\begin{array}{l}\text { Few } \\
\text { animal } \\
\text { studies }\end{array}$ & $\begin{array}{l}\text { No } \\
\text { repeatdose } \\
\text { toxicity } \\
\text { studies }\end{array}$ & $\begin{array}{l}\text { No } \\
\text { carcinogenicity } \\
\text { studies }\end{array}$ & $\begin{array}{l}\text { No } \\
\text { reproductive } \\
\text { toxicity } \\
\text { studies }\end{array}$ & Total \\
\hline 1 & & & 1 & 1 & 1 & 3 \\
\hline 2 & & & & 1 & 1 & 2 \\
\hline 3 & 1 & & & & & 1 \\
\hline 4 & & & 1 & & 1 & 2 \\
\hline 5 & & & & 1 & 1 & 2 \\
\hline 6 & & & & & 1 & 1 \\
\hline 7 & & & 1 & 1 & & 2 \\
\hline 8 & & & 1 & & 1 & 2 \\
\hline 9 & & & & 1 & & 1 \\
\hline 10 & & 1 & & & & 1 \\
\hline 11 & & & & & 1 & 1 \\
\hline 12 & & & 1 & 1 & 1 & 3 \\
\hline 13 & & & & 1 & 1 & 2 \\
\hline 14 & & & & & 1 & 1 \\
\hline 15 & & & & 1 & & 1 \\
\hline 16 & & 1 & & & & 1 \\
\hline 17 & & & & 1 & & 1 \\
\hline 18 & & 1 & & & & 1 \\
\hline 19 & & 1 & & & & 1 \\
\hline 20 & & & & & 1 & 1 \\
\hline 21 & 1 & & & & & 1 \\
\hline 22 & & & 1 & 1 & 1 & 3 \\
\hline 23 & & & & 1 & & 1 \\
\hline 24 & & & & 1 & 1 & 2 \\
\hline 25 & & & 1 & & & 1 \\
\hline 26 & & & 1 & 1 & 1 & 3 \\
\hline 27 & & & 1 & & 1 & 2 \\
\hline 28 & & & 1 & 1 & 1 & 3 \\
\hline 29 & & & & 1 & 1 & 2 \\
\hline Total & 2 & 4 & 10 & 15 & 17 & 48 \\
\hline
\end{tabular}

proposed development program. These manufacturers argued that the risk of reproductive toxicity was negligible (based on the design of the product, based on the target population and/or because clinical data were available) and/or that reproductive toxicity studies in animals were only necessary when the results of biodistribution studies provided reasons for concern. The CHMP did not give a reply in one case. In four scientific advice letters, the CHMP agreed with the approach proposed by the manufacturer, while in eight cases the CHMP stated that more testing or information was necessary to judge whether animal studies could be omitted. The CHMP disagreed once with the line of argumentation of the company and advised conducting reproductive toxicity testing.

\subsection{Application and acceptance of the risk-based approach}

Of the 48 proposals of ATMP developing companies to deviate from the standard requirements and omit animal studies, companies used the argument that no relevant animal model was available ten times (including five times in combination with arguments that the concerned risk was negligible) (Table 4).The analysis showed that $75 \%$ of the proposals (36) to omit non-clinical studies were based on arguments that it was not necessary to con- duct the specific test because the risks (for the target population) were assumed to be negligible.

Fourteen proposals were accepted by the CHMP and in thirteen cases the CHMP stated that additional data was necessary to make an informed decision (Table 5). The CHMP only rejected two proposals to omit animal studies. They rejected two proposals because they did not agree with the line of argumentation provided by the manufacturer. In both cases, the CHMP considered the animal study necessary to learn more about the potential risk.

\section{Discussion}

In this study, scientific advice letters were analyzed to study whether the risk-based approach facilitates science-driven nonclinical drug development. The advantage of using scientific advice letters is that they reflect the current practices and discussions. The disadvantages of using scientific advice letters is that (i) not all companies request scientific advice at the CHMP during the development of ATMPs and (ii) the discussed non-clinical drug development strategies in the scientific advice letters are only proposals and it is unknown whether these proposals will be carried out until the company submits the Marketing Authorisation Application (MAA).

Firstly, requesting scientific advice from the CHMP is optional in the drug development process. Only a portion of the companies developing ATMPs apply for scientific advice. The sample used in this study is likely biased toward complex ATMPs with specific challenges in non-clinical drug development or toward companies aspiring to deviate from the standard requirements. Therefore, this analysis only confirms the use of the risk-based approach in designing the development program of ATMPs and it does not provide information about the extent of the use of the risk-based approach.

Secondly, the development plans proposed by the companies in the scientific advice request might be adapted or completely revised over time. Thus, companies can aspire to apply a risk-based approach at the stage of the scientific advice request, but they can forgo this approach during development. Only when the companies submit the MAA, analyses of the drug registration files will reveal whether the company actually applied a risk-based approach. A follow-up study making use of drug registration files should be done to confirm the results of this study.

\section{Conclusion}

To accommodate the development of ATMPs and to facilitate the design of a science-driven development program for ATMPs, the CHMP recommends companies to use a risk-based approach. To gain insight into the effect of the risk-based approach on the non-clinical development of ATMPs two questions were addressed in this paper. Firstly "Do companies use a risk-based approach in the development of ATMPs?" and, secondly, "Does the Committee for Medicinal Products for Human Use (CHMP) of the EMA accept nonclinical development programs based on the risk-based approach?" 
Table 4

Overview of argumentation to omit animal studies.

\begin{tabular}{|c|c|c|c|c|c|c|c|}
\hline & $\begin{array}{l}\text { No animal } \\
\text { studies }\end{array}$ & $\begin{array}{l}\text { Few animal } \\
\text { studies }\end{array}$ & $\begin{array}{l}\text { No repeat-dose toxicity } \\
\text { studies }\end{array}$ & $\begin{array}{l}\text { No carcinogenicity } \\
\text { studies }\end{array}$ & $\begin{array}{l}\text { No reproductive } \\
\text { toxicity studies }\end{array}$ & Total & $\%$ \\
\hline \multicolumn{8}{|l|}{ Based on risk analyses } \\
\hline Not necessary & 0 & 2 & 8 & 7 & 14 & 31 & 65 \\
\hline Not possible and not necessary & 2 & 0 & 0 & 3 & 0 & 5 & 10 \\
\hline \multicolumn{8}{|l|}{ Not based on risk analyses } \\
\hline Not possible & 0 & 2 & 1 & 1 & 1 & 5 & 10 \\
\hline No argument & 0 & 0 & 1 & 4 & 2 & 7 & 15 \\
\hline
\end{tabular}

Table 5

Classification categories for the answers of the CHMP.

\begin{tabular}{|c|c|c|c|c|c|c|}
\hline & $\begin{array}{l}\text { No animal } \\
\text { studies }\end{array}$ & $\begin{array}{l}\text { Few animal } \\
\text { studies }\end{array}$ & $\begin{array}{l}\text { No repeat dose } \\
\text { toxicity studies }\end{array}$ & $\begin{array}{l}\text { No carcinogenicity } \\
\text { studies }\end{array}$ & $\begin{array}{l}\text { No reproductive } \\
\text { toxicity studies }\end{array}$ & Total \\
\hline Proposal not accepted & & & & 1 & 1 & 2 \\
\hline $\begin{array}{l}\text { More information is necessary to confirm the provided } \\
\text { line of argumentation }\end{array}$ & & & & 5 & 8 & 13 \\
\hline Proposal accepted & 2 & 2 & 2 & 4 & 4 & 14 \\
\hline No response & & & 6 & & 1 & 7 \\
\hline Total & 2 & 2 & 8 & 11 & 14 & 36 \\
\hline
\end{tabular}

Interestingly, the risk-based approach was used to justify deviations from the standard requirements in the majority (75\%) of the proposals. This indicates that companies use the risk-based approach in the development of ATMPs. However, scientific advice for the non-clinical development was requested fifty times, but only 29 times (60\%) companies proposed to deviate from the standard requirements using a risk-based approach. This result indicates that the manufacturers that apply for scientific advice generally do risk analyses and use the risk-based approach as an opportunity to deviate from the requirements as prescribed in Annex I of Directive 2001/83 and the guidelines. However, there is room for broader use of the risk-based approach in the development of ATMPs.

The CHMP accepted $40 \%$ of the proposals directly, while for $35 \%$ of the proposals, the CHMP stated in their responses that additional data is necessary to make an informed decision about omitting a specific study. The CHMP rejected only two proposals to omit animal studies. These findings indicate that application of the riskbased approach for the design of the non-clinical development of ATMPs results in acceptable proposals for the CHMP.

\section{Conflicts of interest}

M. Kooijman, P.J.K. van Meer, E.H.M. Moors, M.P. Hekkert and C.C. Gispen-de Wied declare no conflicts of interest. H. Schellekens participated in meetings and publications sponsored by Amgen, Johnson \& Johnson, Roche, Sandoz and Hospira. Some of his research is directly or indirectly sponsored by Roche and Amgen.

\section{Acknowledgments}

This research was performed under the framework of Top Institute Pharma (project T6-301), which includes the Medicines Evaluation Board, the Organization of Innovative Pharmaceutical Industries in the Netherlands (Nefarma), the Life Science and Health Initiative and Utrecht University. PvM and MK performed this work with the TI Pharma grant. The views expressed in this article are the personal views of the authors and are not to be understood or quoted as being made on behalf of or reflecting the position of the Medicines Evaluation Board or any other regulatory agency, or one of its committees or working parties. The authors would like to thank Spiros Vamvakas for his help in refining the manuscripts.

\section{References}

Cohen-Haguenauer, O., 2013. A comprehensive resource on EU regulatory information for investigators in gene therapy clinical research and advanced therapy medicinal products. Hum. Gene Ther. 24 (1), 12-18.

European Medicines Agency, 2013. Guideline on the risk-based approach according to annex I, part IV of Directive 2001/83/EC applied to advanced therapy medicinal products guideline on the risk-based approach according to annex I, part IV of Directive 2001/83/EC for ATMPs.

European Union, 2001. Directive 2001/83/EC of the European Parliament and of the council of 6 November 2001 on the community code relating to medicinal products for human use (2001).

European Union, 2007. Regulation (EC) No. 1394/2007 of the European Parliament and of the council of 13 November 2007 on advanced therapy medicinal products and amending Directive 2001/83/EC and Regulation (EC) No 726/2004.

Jekerle, V., Schröder, C., Pedone, E., 2010. Legal Basis of the Advanced Therapies Regulation. Bundesgesundheitsblatt, Gesundheitsforschung, Gesundheitsschutz $53(1), 4-8$.

Jilma, B., 2010. Development of advanced therapy medicinal products - a case for early scientific advice. In: Muller, M. (Ed.), Clinical Pharmacology: Current Topics and Case Studies. Springer, Vienna, pp. 323-334.

Klug, B., Celis, P., Carr, M., Reinhardt, J., 2012. Regulatory structures for gene therapy medicinal products in the European Union. Meth. Enzymol. 507, 337-354, 1st ed., Elsevier Inc.

Maciulaitis, R., D’Apote, L., Buchanan, A., Pioppo, L., Schneider, C.K., 2012. Clinical development of advanced therapy medicinal products in Europe: evidence that regulators must be proactive. Mol. Ther. 20 (3), 479-482.

Mavilio, F., 2012. Gene therapies need new development models. Nature 490 (7), 7418

Schneider, C.K., Salmikangas, P., Jilma, B., Flamion, B., Todorova, L.R., Paphitou, A., Haunerova, I., et al., 2010. Challenges with advanced therapy medicinal products and how to meet them. Nat. Rev. Drug Discov. 9 (3), 195-201.

Vamvakas, S., Martinalbo, J., Pita, R., Isaac, M., 2011. On the edge of new technologies (advanced therapies, nanomedicines). Drug Discov. Today Technol. 8 (1), e21-e28. 